\title{
Effects of Nickel Particle Size and Graphene Support on the Electrochemical Performance of Lithium/Dissolved Polysulfide Batteries
}

\author{
Negar Mosavati ${ }^{a}$, Venkateswara Rao Chitturi ${ }^{a}$, Leela Mohana Reddy Arava ${ }^{\mathrm{b}}$, \\ Steven O. Salley ${ }^{a}$, K. Y. Simon $\mathrm{Ng}^{\text {a }}{ }^{*}$ \\ ${ }^{a}$ Department of Chemical Engineering and Materials Science, Wayne State University, \\ Detroit, MI 48202, USA. \\ ${ }^{\mathrm{b}}$ Department of Mechanical Engineering, Wayne State University, Detroit, MI 48202, USA
}

${ }^{*}$ Corresponding Author: (K. Y. Simon Ng).

Tel.: +1313 577 3805; fax: +13135778171.

E-mail address: sng@wayne.edu 


\begin{abstract}
The electrocatalytic effect of nickel (Ni) nanoparticle sizes on the lithium polysulfide conversion reactions in dissolved lithium sulfur battery configuration is investigated. The $\mathrm{Ni}$ particles of $20 \mathrm{~nm}$ with the higher cathode surface area show a superior capacity of 1066 mAh $\mathrm{g}^{-1}$ sulfur compared to Ni particles of 40 and $100 \mathrm{~nm}$ for the first cycle. In addition, to further improve the capacity retention and discharge capacity of the cell, the effect of the graphene support on Ni nanoparticle dispersion and cycling performance is investigated. The results show a significant improvement in the discharge capacity compared to the other electrodes. This could be explained by the homogeneous distribution of Ni nanoparticle within the carbon matrix, which suppress the agglomeration and surface area loss of the $\mathrm{Ni}$ nanoparticle after cycling; as well as a synergetic effect of graphene structure and $\mathrm{Ni}$ nanoparticle.
\end{abstract}

\title{
Keywords
}

Lithium sulfur battery; Polysulfide; Electrocatalyst; Cathode material; Dissolved polysulfide 


\section{Introduction}

Advances in portable electronic devices and electric vehicles requires advanced electrical energy storage systems, such as rechargeable batteries with high energy density and long lasting cycle performance. Among the most promising energy storage systems, lithium sulfur (Li/S) batteries have received increasing attention due to their high energy density of 2600 Wh $\mathrm{kg}^{-1}$ and theoretical capacity of $1675 \mathrm{mAh} \mathrm{g}^{-1}$.[1] In addition, sulfur is environmentally friendly and has a low cost. [1-3] However, the development of lithium sulfur batteries presents some obstacles such as poor cyclability, lower practical capacity and high selfdischarge rate. [1-3] The poor conductivity of sulfur and its final discharge products, $\mathrm{Li}_{2} \mathrm{~S}_{2}$ and $\mathrm{Li}_{2} \mathrm{~S}$, limits the specific capacity of $\mathrm{Li} / \mathrm{S}$ batteries. Furthermore, the dissolution of lithium polysulfide intermediates in the liquid electrolyte during the charge-discharge process causes the polysulfide shuttle process and lithium corrosion, which results in low cyclability, charging inefficiency and high self-discharging rate of batteries $[4,5]$.

In recent years, efforts have been made to improve the performance of Li/S batteries and overcome the above challenges. Much of the research has focused on the development of new cathode materials to enhance the electrical conductivity, to accommodate and absorb polysulfide and active materials within the pores or layers of the cathode structure. In order to improve cathode material performance, conductive carbon additives such as: mesoporous and nano-structured carbon [6-8], porous hollow carbon spheres [9, 10], carbon multi-walled nano-tubes [11, 12], graphene [13,14], conductive polymers [15-17], and carbon interlayers have been used. Several studies have been conducted on the design of alternative current 
collectors such as $\mathrm{Ni}$ foam as an interlayer, cathode conductive structure [18], and a protective layer [19], which improves the active material utilization, cycle life, and battery performance due to its metallicity and 3-D network structure.

It has been reported that the reaction kinetics of aqueous polysulfide can be enhanced by using electrocatalytic electrodes in photoelectrochemical solar cells [20] and redox flow battery cells [21]. Metal oxides such as $\mathrm{CeO}_{2}[22,23], \mathrm{MnO}_{2}$ [24-26], have been demonstrated to be promising cathode catalysts for rechargeable batteries electrochemical reactions. In addition, some metal oxides such as $\mathrm{TiO}_{2}$ [27], $\mathrm{Al}_{2} \mathrm{O}_{3}$ [28], $\mathrm{SiO}_{2}$ [29] and $\mathrm{MnO}_{2}$ [30] have been shown to enhance Li/S discharge capacities and cycling stability. This can be attributed to their strong ability to adsorb sulfur species, thus effectively suppressing the diffusion of polysulfide species into the electrolyte. $\mathrm{Ti}_{4} \mathrm{O}_{7}$ has also been reported to enhance the Li/S batteries redox chemistry due to its sulphiphilic surface and good electron conductivity [5]. In our recent study, carbon-free electrocatalysts such as $\mathrm{Pt}, \mathrm{Au}$ and $\mathrm{Ni}$ has been found to enhance lithium polysulfide conversion reactions and improve Li/S battery performance [31]. Among these electrocatalysts, Ni showed a promising behavior due to its high conductivity along with electrocatalytic activity toward polysulfide reduction reaction. [31] Very few studies have been conducted on lithium polysulfide dissolved configuration with electrocatalytic electrodes. Babu et al. [31] found that with a $200 \mathrm{~nm}$ thick Ni electrode and 10 $\mu \mathrm{l}$ of $0.2 \mathrm{M} \mathrm{Li}_{2} \mathrm{~S}_{8}$ catholyte, a capacity of $420 \mathrm{mAh} \mathrm{g}^{-1}$ sulfur was observed after 40 cycles; while Zhang et al. [32] measured a capacity of $490 \mathrm{mAh} \mathrm{g}^{-1}$ sulfur with a super-p carbon electrode and $20 \mu \mathrm{l}$ of $0.25 \mathrm{~m} \mathrm{Li}_{2} \mathrm{~S}_{9}$ catholyte, also after 40 cycles. In the present study, a series of Ni nanoparticles with nominal particle size of 20,40 , and $100 \mathrm{~nm}$ have been used as electrocatalysts, and the effect of particle size on Li/S battery performance has been 
investigated. Furthermore, graphene has been chosen as a support to anchor the $\mathrm{Ni}$ nanoparticles and to investigate the synergetic effect of carbon material and Ni nanoparticles for the lithium polysulfide conversion reactions. The results indicated there is a strong particle size effect, and Ni/graphene electrode exhibits a capacity of $753 \mathrm{mAh} \mathrm{g}^{-1}$ sulfur after 40 cycles which is significantly higher than similar studies [31, 32].

\section{Experimental}

\subsection{Preparation of electrocatalysts}

Nickel nanoparticles (Ni, 99.9\% with sizes of $20 \mathrm{~nm}, 40 \mathrm{~nm}$ and $100 \mathrm{~nm}$, US Research Nanomaterial Inc.) were activated under hydrogen for $3 \mathrm{~h}$ at $150^{\circ} \mathrm{C}$. To prepare Ni/graphene hybrids, 5 grams of graphene (Angstron Materials) were refluxed with $250 \mathrm{~mL}$ of $70 \% \mathrm{HNO}_{3}$ at $110{ }^{\circ} \mathrm{C}$ for $3 \mathrm{~h}$ to functionalize and also remove metallic impurities. The material was then washed with water and dried at $70{ }^{\circ} \mathrm{C}$ for $12 \mathrm{~h} .0 .8 \mathrm{~g}$ of the functionalized graphene was then stirred with $300 \mathrm{~mL}$ of ethylene glycol, and nickel chloride hexahydrate $\left(\mathrm{NiCl}_{2} \cdot 6 \mathrm{H}_{2} \mathrm{O}\right.$, Sigma Aldrich) was added to the resulting suspension. Ni metal loading on graphene support can be controlled by changing the amount of Ni precursor (nickel chloride hexahydrate $\mathrm{NiCl}_{2} \cdot 6 \mathrm{H}_{2} \mathrm{O}$ ) during the preparation. In the present work, we have used $0.81 \mathrm{~g}$ of nickel chloride hexahydrate $\left(\mathrm{NiCl}_{2} \cdot 6 \mathrm{H}_{2} \mathrm{O}\right)$ to achieve Ni metal loading of $20 \mathrm{wt} . \%$ on graphene. The resulting suspension was then heated to $140{ }^{\circ} \mathrm{C}$ and held for $10 \mathrm{~min}$. Thereafter, $0.65 \mathrm{~g}$ sodium borohydride $\left(\mathrm{NaBH}_{4}\right.$, Sigma Aldrich) dissolved in $20 \mathrm{~mL}$ of ethylene glycol was slowly added and refluxed for $2 \mathrm{~h}$. Finally, the solution was filtered, washed with water/ethanol, and dried overnight. 


\subsection{Fabrication of electrodes and electrochemical measurements}

The cathode slurry was prepared by adding $10 \mathrm{wt} \%$ of poly(acrylonitrile-methyl methacrylate) (Polysciences Inc) AN/MMA=94:6, as binder and N-methyl pyrrolidinone (NMP) as solvent to the electrocatalyst materials (Ni nanoparticles, Ni/graphene, or graphene). The slurry was coated on Al foil and dried at $80{ }^{\circ} \mathrm{C}$ under vacuum for $10 \mathrm{~h}$.

Elemental sulfur $\mathrm{S}_{8}$, lithium sulfide $\mathrm{Li}_{2} \mathrm{~S}$, Bis(trifluoromethane)sulfonimide lithium salt $\mathrm{LiN}\left(\mathrm{SO}_{2} \mathrm{CF}_{3}\right)_{2}$, LiTFSI, Triethylene glycol dimethyl ether $\left(\mathrm{TG}_{3}\right)$, were purchased from Aldrich and used as received. A catholyte solution with $0.2 \mathrm{M} \mathrm{Li}_{2} \mathrm{~S}_{8}, 0.1 \mathrm{M} \mathrm{LiTFSI}$, and $1 \mathrm{M} \mathrm{LiNO}_{3}$ was prepared by stirring appropriate amounts of $\mathrm{S}_{8}$ and $\mathrm{Li}_{2} \mathrm{~S}$ into $\mathrm{TG}_{3}$ at $80{ }^{\circ} \mathrm{C}$ for $6 \mathrm{~h} .10 \mu \mathrm{L}$ of $0.2 \mathrm{M} \mathrm{Li}_{2} \mathrm{~S}_{8}$ catholyte solution containing $0.54 \mathrm{mg}$ sulfur was added onto positive electrodes with $8 \mathrm{mg} \mathrm{Ni} \mathrm{cm}^{-2}$ loading. In addition, a Polypropylene separator (Celgard 2400), and lithium foil anode were used to assemble coin cells (CR2032) inside an argon filled glove box. The effect of catholyte concentration on $\mathrm{Ni}$ catalyst has been investigated in our recent study on a $200 \mathrm{~nm}$ Ni film, with 100,200 and $600 \mathrm{mM}$ of $\mathrm{Li}_{2} \mathrm{~S}_{8}$ catholyte concentration at 0.1 C rate [31]. The results shows a decrease in specific capacity with increase in the concentration of polysulfide due to increase in the electrolyte viscosity. Therefore, $0.2 \mathrm{M}$ electrolyte was used in the present study.

\subsection{Characterization and electrochemical measurements}

Phase purity of the positive electrode materials was characterized using a Rigaku Miniflex 600 X-Ray Diffractometer. Morphological features of the cathodes before and after cycling 
were observed with field emission scanning electron microscopy (JEOL 7600F, FESEM). The specific surface area analyses were measured by Braunauer-Emmet-Teller (BET) multimolecular adsorption method (Micromeritics Tristar II surface area/porosimeter). Galvanostatic discharge-charge tests were conducted using a Maccor Model 4200 Automated Test System between the voltage range of 1.5 to $3 \mathrm{~V}\left(\mathrm{vs}\right.$. $\mathrm{Li}^{\prime} / \mathrm{Li}^{+}$) at room temperature. Cyclic voltammetry experiments were performed using a Gamry potentiostat reference 3000 at different scan rates ranging from 0.05 to $1 \mathrm{mV} \mathrm{s}^{-1}$ in the voltage range of 3 to $1.5 \mathrm{~V}\left(\mathrm{vs} . \mathrm{Li} / \mathrm{Li}^{+}\right)$.

\section{Results and discussion}

\subsection{Structure and morphology}

SEM images of the Ni nanoparticles, graphene and graphene supported Ni nanoparticles were recorded at high magnification and show the uniform distribution of the spherical shaped Ni nanoparticles (Figure 1a-c). The average particle size was calculated from the measurement of about 250 particles found in an arbitrarily chosen area of the enlarged images. It was found to be about 17, 38, and $92 \mathrm{~nm}$ for the nominal 20, 40, and $100 \mathrm{~nm} \mathrm{Ni}$ nanoparticles, respectively. In the case of Ni/graphene, average size of about $11 \mathrm{~nm} \mathrm{Ni}$ nanoparticles are homogeneously distributed within the graphene matrix (Figure 1d). It was also confirmed from the corresponding EDS mapping images shown in Fig. S1 (supplementary info).

The surface area of Ni nanoparticles was measured by BET sorptometry and results are provided in (Figure 1e). As expected, the surface area of $20 \mathrm{~nm}$ size Ni nanoparticles is 28.9 
$\mathrm{m}^{2} \mathrm{~g}^{-1}$ which is higher than 3.6 and $2.7 \mathrm{~m}^{2} \mathrm{~g}^{-1}$ for the 40 and $100 \mathrm{~nm} \mathrm{Ni}$ nanoparticles, respectively. Crystal structure of the nanostructured electrocatalysts is analyzed by XRD. Figure 1f shows the XRD pattern of $\mathrm{Ni}$ nanoparticles and the graphene supported $\mathrm{Ni}$ nanoparticles. A face-centered cubic phase Ni diffraction pattern without any other peaks was observed for all of the samples, which indicates that the Ni nanoparticles are single-phase fcc. Ni crystallite size is determined using Scherrer's equation and considering the full width at half maximum (FWHM) of all the Ni diffraction peaks, the average Ni crystallite sizes are calculated to be $10,20,39$, and $58 \mathrm{~nm}$ for the Ni/graphene, 20, 40, and $100 \mathrm{~nm} \mathrm{Ni}$ nanoparticles, respectively.

\subsection{Electrochemical performances}

In order to have a better understanding of $\mathrm{Ni}$ electrocatalyst activity towards polysulfides conversion reaction, cyclic voltammograms were performed at different scan rates from 0.05 to $1 \mathrm{mV} \mathrm{s}^{-1}$. All cycles present one anodic oxidation peak at $2.54 \mathrm{~V}\left(\mathrm{vs}\right.$. $\mathrm{Li}^{2} / \mathrm{Li}^{+}$) and two cathodic reduction peaks at 2.0 and $2.4 \mathrm{~V}\left(\mathrm{vs}\right.$. $\left.\mathrm{Li} / \mathrm{Li}^{+}\right)$. The higher voltage cathodic peak corresponds to the conversion of sulfur to higher order lithium polysulfide $\left(\mathrm{Li}_{2} \mathrm{~S}_{n} \mathrm{n}>4\right)$ and the lower voltage cathodic peak represents the transformation of dissolved higher order lithium polysulfide to insoluble lower order lithium polysulfide $\left(\mathrm{Li}_{2} \mathrm{~S}_{n} \mathrm{n}<4\right)$ [1]. (Figure 2). The $20 \mathrm{~nm}$ $\mathrm{Ni}$ nanoparticle electrode shows a more stable behavior for polysulfide conversion reaction during the first 4 cycles (Figure 2a). In addition, Graphene electrode without $\mathrm{Ni}$ also exhibited similar redox behavior (Fig. S2). Figure 3 shows the cyclic voltammograms at different scan rates. Anodic and cathodic peak positions shift toward higher and lower voltage, respectively, 
as scan rate increases, which indicates the quasi-reversible nature of polysulfide reactions [33]. Furthermore, the Randlese-Sevcik are shown a linear relationship of the cathodic peak height as a function of the square root of the scanning rate, which clearly indicates that polysulfide conversion reaction are diffusion controlled [34].

Figure 4a-c presents the charge and discharge voltage profile of Ni electrodes at a $0.1 \mathrm{C}$ rate. All of the discharge curves present two plateaus in the voltage range of 2.0 to $2.4 \mathrm{~V}$ (vs. $\mathrm{Li}^{\mathrm{L}} \mathrm{Li}^{+}$), which are in good accordance with the two cathodic peaks in the charge voltage curves (Figure 2). It is known that one of the factors determining electrocatalytic activity is the accessible surface area [35]. Therefore, the $20 \mathrm{~nm}$ Ni particles electrode with higher surface area displays a high initial discharge capacity of $1067 \mathrm{mAh} \mathrm{g}^{-1}$ sulfur, contrasting with the 580 and $496 \mathrm{mAh} \mathrm{g}^{-1}$ sulfur discharge capacity of the $40 \mathrm{~nm}$ and $100 \mathrm{~nm}$ electrodes, respectively. In addition, after 40 cycles, the electrode with $20 \mathrm{~nm}$ shows the highest discharge capacity of $583 \mathrm{mAh} \mathrm{g}^{-1}$ sulfur, compared to the 493 and $298 \mathrm{mAh} \mathrm{g}^{-1}$ sulfur capacity of the $40 \mathrm{~nm}$ and $100 \mathrm{~nm}$ electrodes, respectively. In order to further improve the capacity retention and discharge capacity of the cell, the effect of the graphene support to anchor the Ni nanoparticle has been investigated. The capacity performance of the cell with $\mathrm{Ni} /$ graphene electrode is significantly improved to a high initial capacity of $1216 \mathrm{mAh} \mathrm{g}^{-1}$ sulfur compared to $766 \mathrm{mAh} \mathrm{g}^{-1}$ sulfur capacity of graphene electrode. Ni/graphene electrode and graphene electrode capacities decreased to 753 , and $408 \mathrm{mAh} \mathrm{g}^{-1}$ sulfur after 40 cycles (Figure $4 \mathrm{~d}$ ). In addition, capacity retention of the $\mathrm{Ni} /$ graphene electrode is around 10 percent higher than graphene electrode during 40 cycles. Moreover, we have demonstrated Ni electrochemical activity by investigating the effect of polysulfide concentration and temperature on Li/S battery performance in our recent study [31]. Therefore, the superior Ni/graphene cell performance 
can be attributed to the synergetic effect of both $\mathrm{Ni}$ nanoparticle catalyst and graphene structure. Moreover, the homogeneous distribution of Ni nanoparticle within the carbon matrix can minimize the agglomeration of the Ni nanoparticle which decreases the surface area loss after cycling.

Regarding the quasi-reversible nature of polysulfide reactions and the formation of passivation layer on positive electrode and lithium surface, the original mass of active sulfur on the positive electrode can become lower during cycling which is one of the main reasons of capacity fade after cycling. Although the capacity of all electrodes decreases with cycling, the $\mathrm{Ni} / g r a p h e n e$ electrode has the highest capacity after 40 cycles compared to all of the other electrodes (Figure 5a). The rate capability of the Ni electrodes is presented in Figure 5b. The C rate is based on the theoretical capacity of sulfur ( $\mathrm{C}=1675 \mathrm{mAh} \mathrm{g}^{-1}$ sulfur). All of the electrodes were first subjected to a low $0.1 \mathrm{C}$ rate to obtain stable nominal capacity. Subsequent cycling was performed at higher current rates of $0.2,0.5$, and $1.0 \mathrm{C}$, each for 5 cycles. Finally, it was operated at $0.1 \mathrm{C}$ for more 6 cycles. The capacity of all of the $\mathrm{Ni}$ electrodes decreases with increasing cycle numbers. The Ni/graphene cell shows a higher capacity performance of $1170,827,629$, and $489 \mathrm{mAh} \mathrm{g}^{-1}$ sulfur, compared to the other electrodes at $0.1,0.2,0.5$, and $1.0 \mathrm{C}$ rates, respectively. All of the cells recovered most of their capacity when the current rate was returned back to $0.1 \mathrm{C}$.

\subsection{Morphological changes of the cathodes}

The cathode electrode was completely washed with TG3 prior to SEM measurements to remove the soluble polysulfides. Figure 6 shows the SEM images of the Ni nanoparticle, graphene, and graphene supported Ni nanoparticle electrodes before and after cycling. After 
the $40^{\text {th }}$ full charge process, a passivation layer is observed on the particle surface, which appears to be thinner in the 40 and $100 \mathrm{~nm}$ nanoparticle electrodes. The formation of this layer, which is reported to be mostly lithium sulfide $\mathrm{Li}_{2} \mathrm{~S}$ [36-41], may reduce the cell performance in several ways. It diminishes the interfacial property between the electrodes and electrolyte [40]. In addition, while the polysulfide reactions occur at the surface of the electrode, the insulating nature of the passivation layer may cause a capacity fade [38]. Furthermore, this passivation layer decreases the electrochemical active surface area of the electrode. More importantly, the precipitated $\mathrm{Li}_{2} \mathrm{~S}$ in the cathode matrix at fully charged state does not contribute to discharge capacity and can be regarded as irreversible loss of active material [41]. There may be a possibility for the formation of $\mathrm{NiS}_{\mathrm{x}}$ during the charge-discharge process. However, the formation of NiSx was not reported in Nickel foam and Ni film that have been used in Li/S batteries. [18, 31]

Therefore, the capacity fade in the cases of the $\mathrm{Ni} 20 \mathrm{~nm}$ and Ni/graphene electrodes are more significant compared to the other electrodes. These results are in a very good agreement with the electrochemical measurement.

\section{Conclusions}

The effects of $\mathrm{Ni}$ particle size and graphene support on the lithium polysulfide conversion reactions and Li/S battery performance have been studied. The results indicate the $20 \mathrm{~nm} \mathrm{Ni}$ electrode with higher surface area has good electrochemical performance. Moreover, the 40 $\mathrm{nm} \mathrm{Ni}$ electrode shows more superior stability, which is possibly because of thinner passivation layer formation and less morphological changes of the positive electrode. $\mathrm{Ni} / g r a p h e n e$ electrode exhibited higher initial capacity and capacity retention compared to the 
graphene electrode. This is probably due to the better dispersion of $\mathrm{Ni}$ nanoparticles on graphene support, large surface-volume ratio and synergetic effect of graphene and $\mathrm{Ni}$.

\section{Acknowledgment}

Financial support from the Department of Energy (Grant DE-EE0002106) is gratefully acknowledged.

[1] S.S. Zhang, Liquid electrolyte lithium/sulfur battery: Fundamental chemistry, problems, and solutions, Journal of Power Sources, 231 (2013) 153-162.

[2] Y.F. Arumugam Manthiram , and Yu-Sheng Su, <review.pdf>, ACS, 46 (2013) 1125-1134. [3] D. Bresser, S. Passerini, B. Scrosati, Recent progress and remaining challenges in sulfurbased lithium secondary batteries--a review, Chemical communications, 49 (2013) 1054510562.

[4] S.-H. Chung, A. Manthiram, Lithium-sulfur batteries with superior cycle stability by employing porous current collectors, Electrochimica Acta, 107 (2013) 569-576.

[5] Q. Pang, D. Kundu, M. Cuisinier, L.F. Nazar, Surface-enhanced redox chemistry of polysulphides on a metallic and polar host for lithium-sulphur batteries, Nat Commun, 5 (2014).

[6] X. Ji, K.T. Lee, L.F. Nazar, A highly ordered nanostructured carbon-sulphur cathode for lithium-sulphur batteries, Nat Mater, 8 (2009) 500-506.

[7] J. Wang, S.Y. Chew, Z.W. Zhao, S. Ashraf, D. Wexler, J. Chen, S.H. Ng, S.L. Chou, H.K. Liu, Sulfur-mesoporous carbon composites in conjunction with a novel ionic liquid electrolyte for lithium rechargeable batteries, Carbon, 46 (2008) 229-235.

[8] C. Liang, N.J. Dudney, J.Y. Howe, Hierarchically Structured Sulfur/Carbon Nanocomposite Material for High-Energy Lithium Battery, Chemistry of Materials, 21 (2009) 4724-4730.

[9] N. Jayaprakash, J. Shen, S.S. Moganty, A. Corona, L.A. Archer, Porous Hollow Carbon@Sulfur Composites for High-Power Lithium-Sulfur Batteries, Angewandte Chemie International Edition, 50 (2011) 5904-5908.

[10] G. He, S. Evers, X. Liang, M. Cuisinier, A. Garsuch, L.F. Nazar, Tailoring Porosity in Carbon Nanospheres for Lithium-Sulfur Battery Cathodes, ACS Nano, 7 (2013) 1092010930.

[11] S.-C. Han, M.-S. Song, H. Lee, H.-S. Kim, H.-J. Ahn, J.-Y. Lee, Effect of Multiwalled Carbon Nanotubes on Electrochemical Properties of Lithium/Sulfur Rechargeable Batteries, Journal of The Electrochemical Society, 150 (2003) A889-A893. 
[12] L. Yuan, H. Yuan, X. Qiu, L. Chen, W. Zhu, Improvement of cycle property of sulfurcoated multi-walled carbon nanotubes composite cathode for lithium/sulfur batteries, Journal of Power Sources, 189 (2009) 1141-1146.

[13] S. Evers, L.F. Nazar, Graphene-enveloped sulfur in a one pot reaction: a cathode with good coulombic efficiency and high practical sulfur content, Chemical Communications, 48 (2012) 1233-1235.

[14] H. Wang, Y. Yang, Y. Liang, J.T. Robinson, Y. Li, A. Jackson, Y. Cui, H. Dai, GrapheneWrapped Sulfur Particles as a Rechargeable Lithium-Sulfur Battery Cathode Material with High Capacity and Cycling Stability, Nano Letters, 11 (2011) 2644-2647.

[15] Y. Fu, A. Manthiram, Orthorhombic Bipyramidal Sulfur Coated with Polypyrrole Nanolayers As a Cathode Material for Lithium-Sulfur Batteries, The Journal of Physical Chemistry C, 116 (2012) 8910-8915.

[16] L. Xiao, Y. Cao, J. Xiao, B. Schwenzer, M.H. Engelhard, L.V. Saraf, Z. Nie, G.J. Exarhos, J. Liu, A Soft Approach to Encapsulate Sulfur: Polyaniline Nanotubes for Lithium-Sulfur Batteries with Long Cycle Life, Advanced Materials, 24 (2012) 1176-1181.

[17] J. Wang, J. Chen, K. Konstantinov, L. Zhao, S.H. Ng, G.X. Wang, Z.P. Guo, H.K. Liu, Sulphur-polypyrrole composite positive electrode materials for rechargeable lithium batteries, Electrochimica Acta, 51 (2006) 4634-4638.

[18] K. Zhang, F. Qin, J. Fang, Q. Li, M. Jia, Y. Lai, Z. Zhang, J. Li, Nickel foam as interlayer to improve the performance of lithium-sulfur battery, J Solid State Electrochem, 18 (2014) 1025-1029.

[19] J. Hassoun, M. Agostini, A. Latini, S. Panero, Y.-K. Sun, B. Scrosati, Nickel-Layer Protected, Carbon-Coated Sulfur Electrode for Lithium Battery, Journal of The Electrochemical Society, 159 (2012) A390-A395.

[20] Daniel V. Esposito, Kevin D. Dobson, Brian E. McCandless, Robert W. Birkmire, J.G. Chen, Comparative Study of Tungsten Monocarbide and Platinum as Counter Electrodes in Polysulfide-Based Photoelectrochemical Solar Cells, Journal of The Electrochemical Society, 156 (2009) B962-B969.

[21] P. Zhao, H. Zhang, H. Zhoua, B. Yi, Nickel foam and carbon felt applications for sodium polysulfide/bromine redox flow battery electrodes, Electrochimica Acta, 51 (2005) 10911098.

[22] Y. Zhu, S. Liu, C. Jin, S. Bie, R. Yang, J. Wua, MnOx decorated $\mathrm{CeO} 2$ nanorods as cathode catalyst for rechargeable lithium-air batteries†, J. Mater. Chem. A, 3 (2015) 1356313567.

[23] J.A. Haber, E. Anzenburg, J. Yano, C. Kisielowski, J.M. Gregoire, Multiphase Nanostructure of a Quinary Metal Oxide Electrocatalyst Reveals a New Direction for OER Electrocatalyst Design, Adv. Energy Mater., 5 (2013).

[24] L. Trahey, N.K. Karan, M.K.Y. Chan, J. Lu, Y. Ren, J. Greeley, M. Balasubramanian, A.K. Burrell, L.A. Curtiss, M.M. Thackeray, Synthesis, Characterization, and Structural Modeling of High-Capacity, Dual Functioning MnO 2 Electrode/ Electrocatalysts for Li-O 2 Cells, Adv. Energy Mater., 3 (2013) 75-84.

[25] P. Zhang, D. Sun, M. He, J. Lang, S. Xu, X. Yan, Synthesis of Porous delta-MnO2 Submicron Tubes as Highly Efficient Electrocatalyst for Rechargeable Li-O2 Batteries, ChemSusChem, 8 (2015) 1972-1979.

[26] M.Z. Zheng Huang, Junfang Cheng, Yingpeng Gong, Xi Li, Bo Chi, Jian Pu, Li Jian, Silver decorated beta-manganese oxide nanorods as an effective cathode electrocatalyst for 
rechargeable lithium-oxygen battery, Journal of Alloys and Compounds, 626 (2015) 173179.

[27] S. Evers, T. Yim, L.F. Nazar, Understanding the Nature of Absorption/Adsorption in Nanoporous Polysulfide Sorbents for the Li-S Battery, The Journal of Physical Chemistry C, 116 (2012) 19653-19658.

[28] J.R. SMITH, F.C. WALSH, Electrodes based on MagneÂ li phase titanium oxides: the properties and applications of EbonexÒ materials, J Appl Electrochem, 28 (1998) 1021-1033. [29] X. Ji, S. Evers, R. Black, L.F. Nazar, Stabilizing lithium-sulphur cathodes using polysulphide reservoirs, Nat Commun, 2 (2011) 325.

[30] S. Wang, Z. Yang, H. Zhang, H. Tan, J. Yu, J. Wu, Mesoporous MnO2/sulfur composite as cathode material for Li-S batteries, Electrochimica Acta, 106 (2013) 307-311.

[31] G. Babu, K. Ababtain, K.Y.S. Ng, L.M.R. Arava, Electrocatalysis of Lithium Polysulfides: Current Collectors as Electrodes in Li/S Battery Configuration, Sci. Rep., 5 (2015).

[32] S.S. Zhang, J.A. Read, A new direction for the performance improvement of rechargeable lithium/sulfur batteries, Journal of Power Sources, 200 (2012) 77-82.

[33] Y. Munaiah, S. Suresh, S. Dheenadayalan, V.K. Pillai, P. Ragupathy, Comparative Electrocatalytic Performance of Single-Walled and Multiwalled Carbon Nanotubes for Zinc Bromine Redox Flow Batteries, The Journal of Physical Chemistry C, 118 (2014) 1479514804.

[34] L. Wang, H.R. Byon, N-Methyl-N-propylpiperidinium bis(trifluoromethanesulfonyl)imidebased organic electrolyte for high performance lithium-sulfur batteries, Journal of Power Sources, 236 (2013) 207-214.

[35] A.L.M. Reddy, M.M. Shaijumon, N. Rajalakshmi, S. Ramaprabhu, Performance of Proton Exchange Membrane Fuel Cells Using Pt/MWNT-Pt/C Composites as Electrocatalysts for Oxygen Reduction Reaction in Proton Exchange Membrane Fuel Cells, Journal of Fuel Cell Science and Technology, 7 (2009) 021001-021001.

[36] D.-R. Chang, S.-H. Lee, S.-W. Kim, H.-T. Kim, Binary electrolyte based on tetra(ethylene glycol) dimethyl ether and 1,3-dioxolane for lithium-sulfur battery, Journal of Power Sources, 112 (2002) 452-460.

[37] S. Dorfler, M. Hagen, H. Althues, J. Tubke, S. Kaskel, M.J. Hoffmann, High capacity vertical aligned carbon nanotube/sulfur composite cathodes for lithium-sulfur batteries, Chemical Communications, 48 (2012) 4097-4099.

[38] R. Elazari, G. Salitra, Y. Talyosef, J. Grinblat, C. Scordilis-Kelley, A. Xiao, J. Affinito, D. Aurbach, Morphological and Structural Studies of Composite Sulfur Electrodes upon Cycling by HRTEM, AFM and Raman Spectroscopy, Journal of The Electrochemical Society, 157 (2010) A1131-A1138.

[39] V.S. Kolosnitsyn, E.V. Kuzmina, S.E. Mochalov, Determination of lithium sulphur batteries internal resistance by the pulsed method during galvanostatic cycling, Journal of Power Sources, 252 (2014) 28-34.

[40] W. Wang, Y. Wang, Y. Huang, C. Huang, Z. Yu, H. Zhang, A. Wang, K. Yuan, The electrochemical performance of lithium-sulfur batteries with LiClO4 DOL/DME electrolyte, J Appl Electrochem, 40 (2010) 321-325.

[41] S.-E. Cheon, K.-S. Ko, J.-H. Cho, S.-W. Kim, E.-Y. Chin, H.-T. Kim, Rechargeable Lithium Sulfur Battery: I. Structural Change of Sulfur Cathode During Discharge and Charge, Journal of The Electrochemical Society, 150 (2003) A796-A799. 


\section{List of Figure Captions}

Figure 1. SEM images of $\mathrm{Ni}$ nanoparticles: (a) $20 \mathrm{~nm}$, (b) $40 \mathrm{~nm}$, (c) $100 \mathrm{~nm}$, (d) $\mathrm{Ni} / G r a p h e n e,(e)$ BET surface area of Ni nanoparticles, and (f) XRD patterns of all of the nanoparticles.

Figure 2. Voltammograms for first 4 cycles: (a) Ni $20 \mathrm{~nm}$, (b) Ni $40 \mathrm{~nm}$, (c) Ni $100 \mathrm{~nm}$, and (d) $\mathrm{Ni} /$ Graphene

Figure 3. Cyclic voltammograms at different scan rates $\left(0.05\right.$ to $1 \mathrm{mV} \mathrm{s}^{-1}$ ): (a) $\mathrm{Ni} 20 \mathrm{~nm}$, (b) $\mathrm{Ni} 40 \mathrm{~nm}$, (c) Ni $100 \mathrm{~nm}$, and (d) Ni/Graphene.

Figure 4. Voltage vs specific capacity profiles at different cycles: (a) Ni $20 \mathrm{~nm}$, (b) Ni $40 \mathrm{~nm}$, (c) Ni 100 nm, (d) Ni/Graphene, and (e) Graphene.

Figure 5. Effect of particle size and graphene support on cycling performance: (a) Capacity performance, and (b) Rate capability at different current rates.

Figure 6. Images of electrodes before cycling (left column), and after 40 cycles (right column): (a) Ni 20 nm, (b) Ni 40 nm, (c) Ni 100 nm, and (d) Ni/Graphene. 

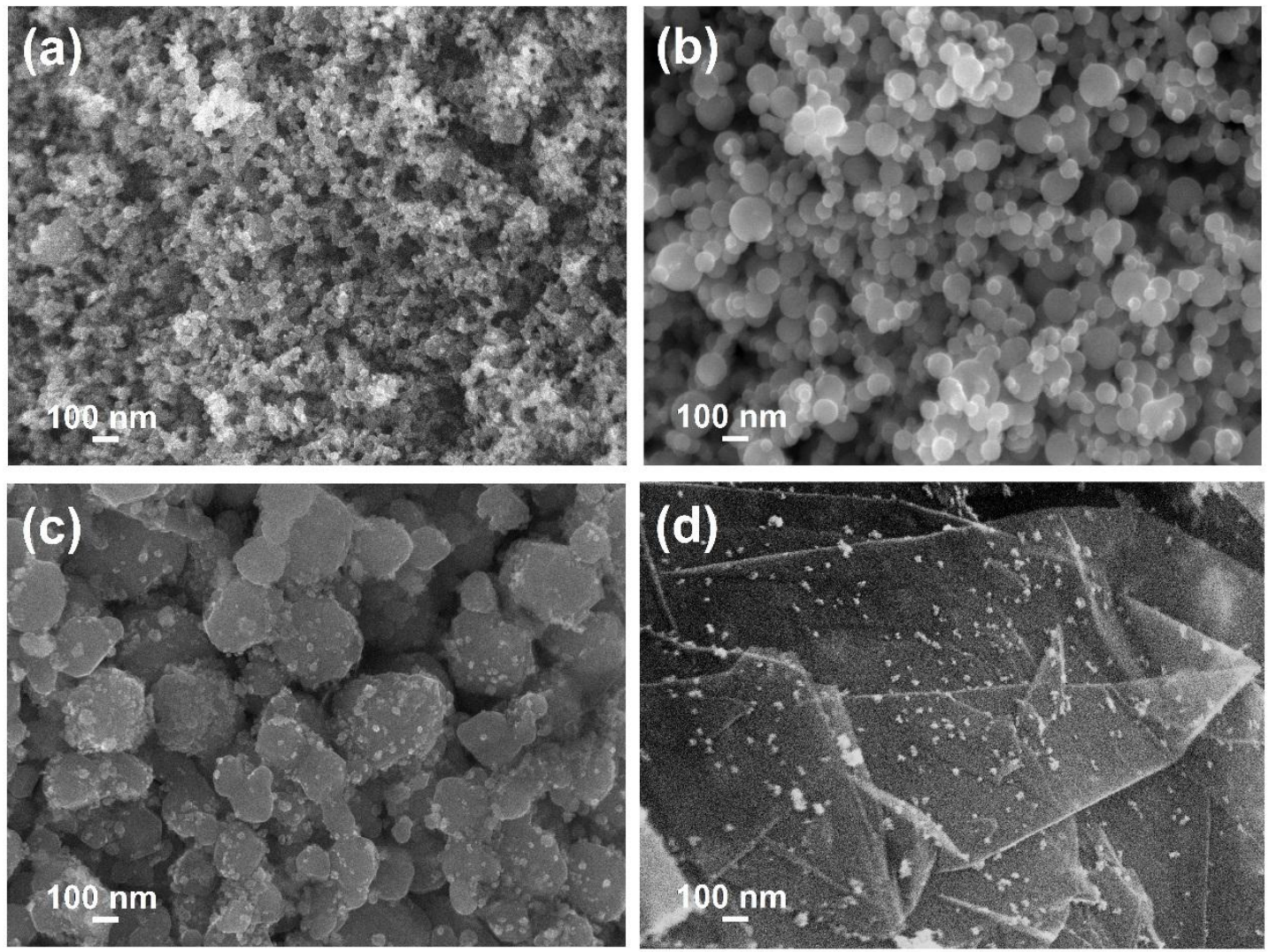

(e)

\begin{tabular}{|c|c|}
\hline $\begin{array}{c}\text { Ni particle size } \\
(\mathrm{nm})\end{array}$ & $\begin{array}{c}\text { BET surface } \\
\text { area }\left(\mathrm{m}^{2} / \mathrm{g}\right)\end{array}$ \\
\hline 20 & 28.9 \\
\hline 40 & 3.6 \\
\hline 100 & 2.7 \\
\hline
\end{tabular}

(f)

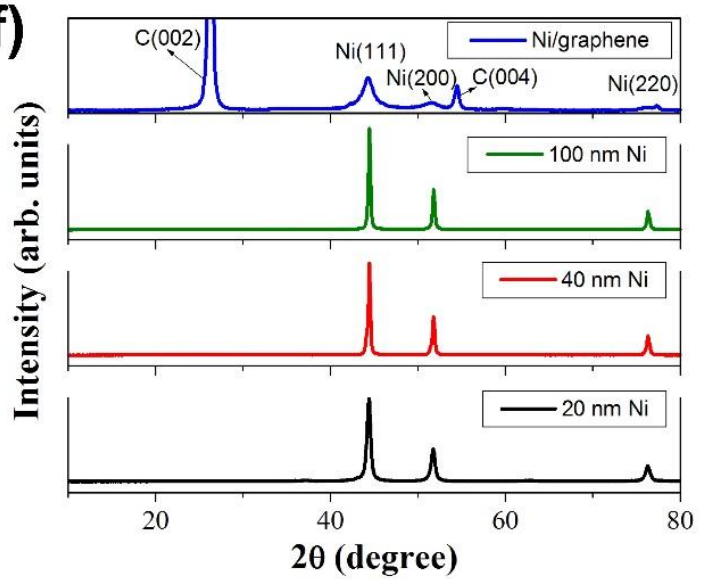

Figure 1 

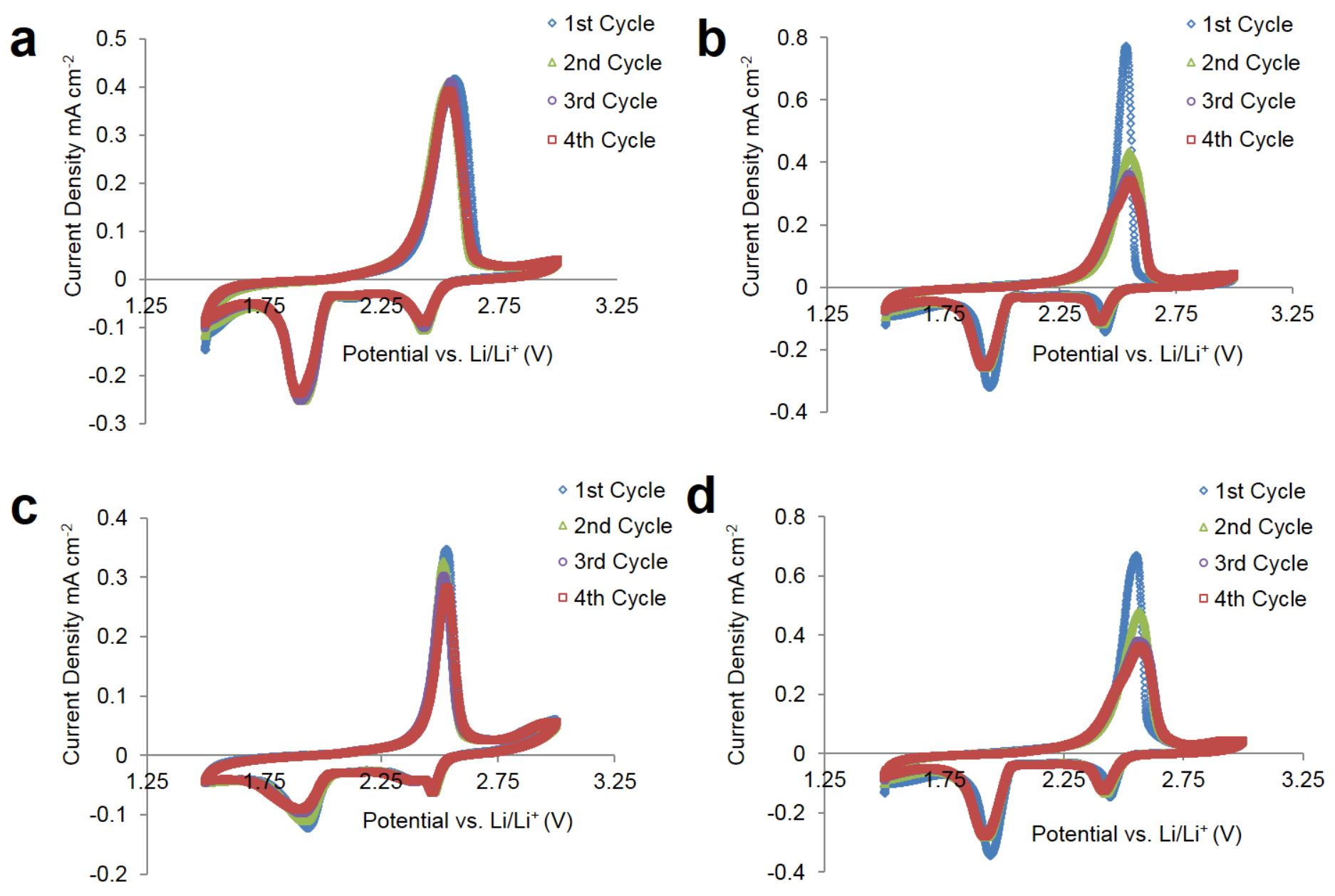

Figure 2 

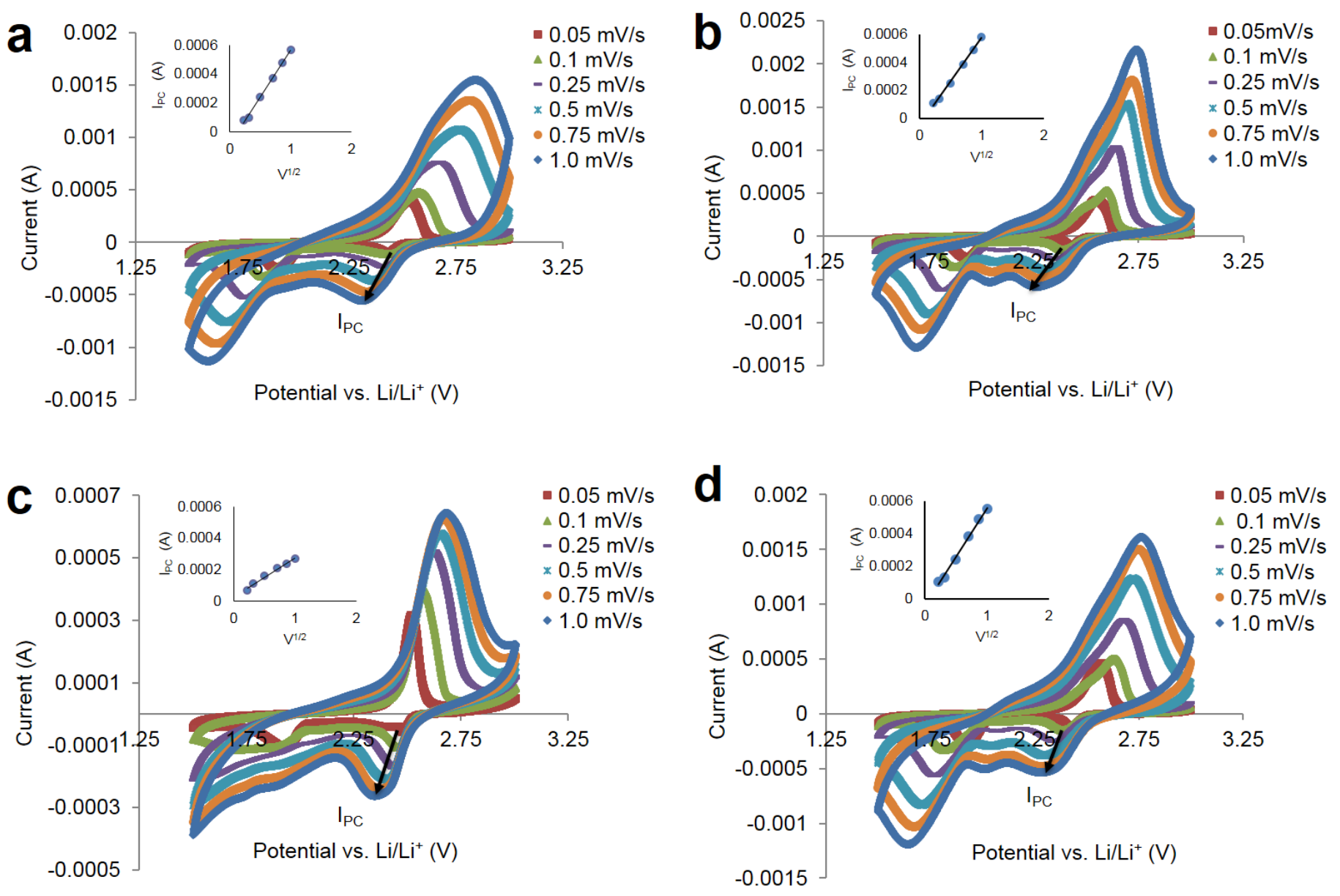

Figure 3 

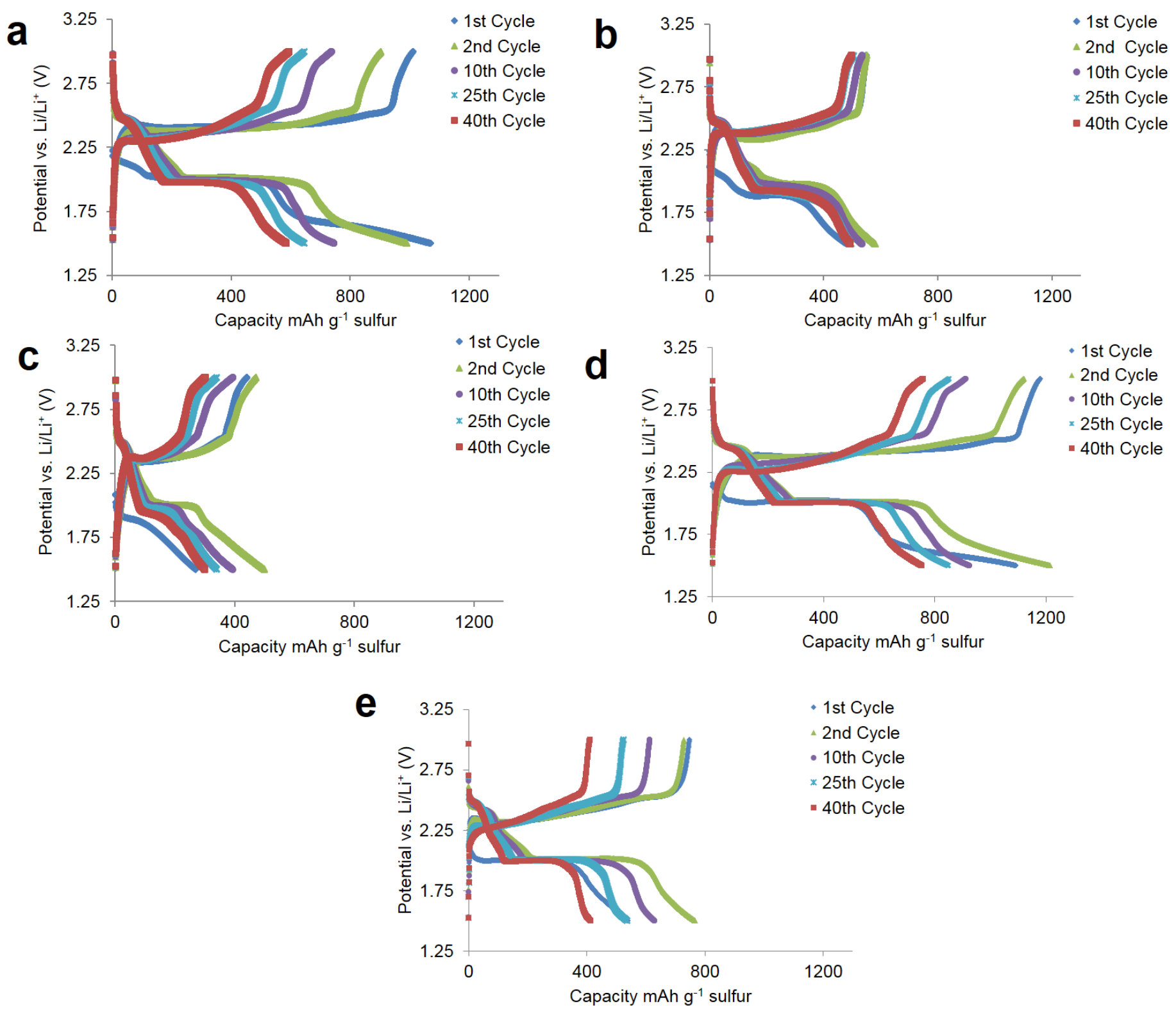

Figure 4 

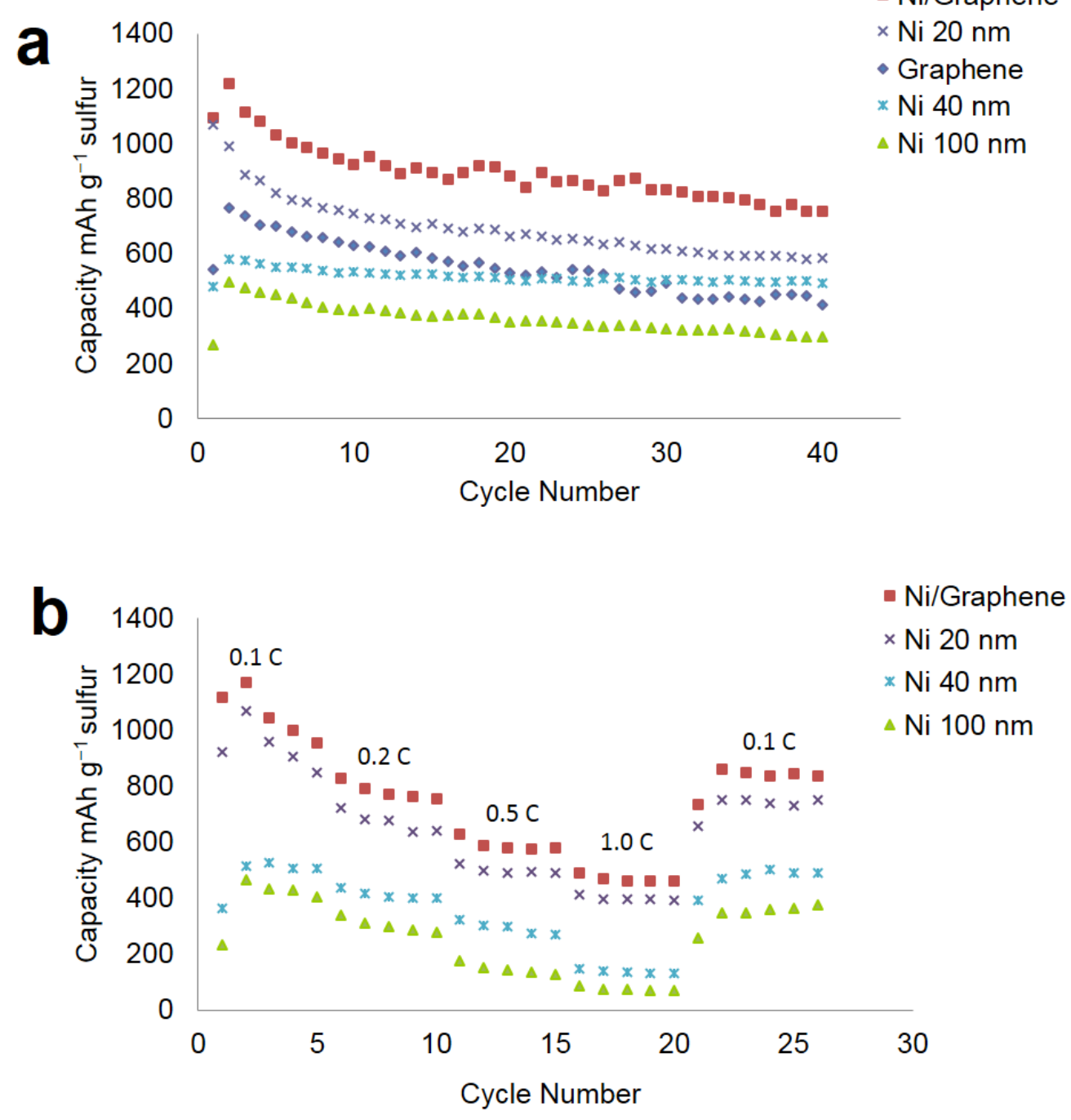

Figure 5 


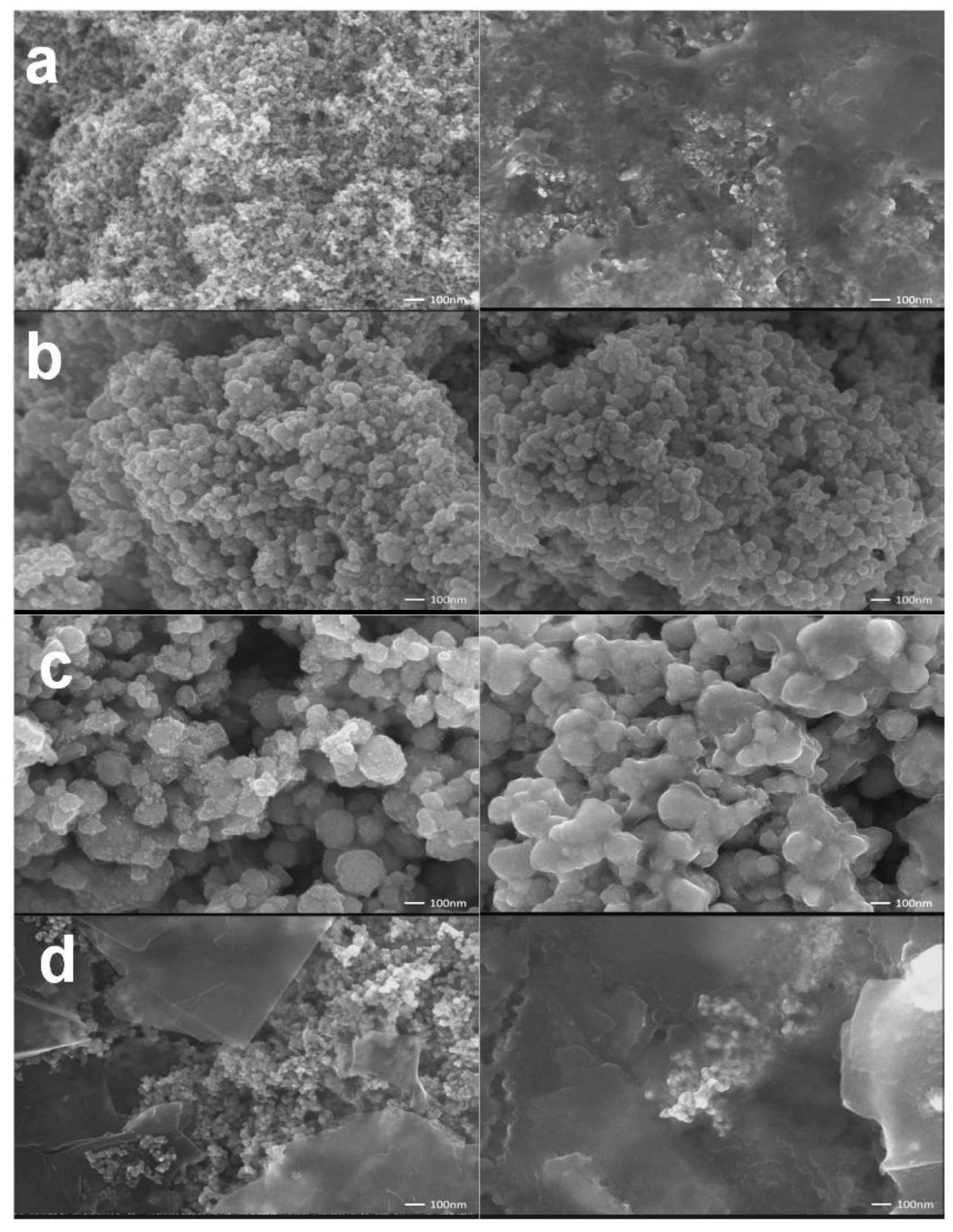

Figure 6 